\title{
Research on the Construction of the Emergency Logistics System in the Large State-Owned Enterprises
}

\author{
Lan Fu \\ Statistics School, Jiangxi University of Finance of Economics, Nanchang, China \\ Email: fulan60010068@sina.com
}

Received May 2014

\begin{abstract}
The purpose of this essay is to discuss some issues about the government how to improve the construction of the infrastructures, transportation system and communication system and how to enhance the capability of resisting natural disaster as the disaster comes. Emergent logistics information system not only can help the power group to collect information and forecast the future disaster but also has the function of decision-making and supporting. Furthermore the emergency logistics information system can assist the power group to decrease the loss from the disaster.
\end{abstract}

\section{Keywords}

\section{Power Group, Emergency Logistics, Logistics Information System}

\section{Introduction}

A catastrophic natural disaster, a rare continuous low temperature, sleet and frost on record occurred in the central of China in late January 2008. It caused tremendous damage for the power grid in China. Due to the ice thickness of transmission line is far more than its design standard. This led to the fall of pole (tower), the break of the wire and the outage. In order to repair and reconstruct damaged power facilities as soon as possible, the government had to organize production and transportation for the power facilities in a short period of time [1].

\subsection{The Main Emergency Measures Are Showed in the Following Aspects}

The first measure is to integrate the existing relief stocks and the rules of the reserve warehouse in the different departments. For reserves relief materials and reserve warehouse adopt classification and assortment management. Regarding to the reserve rules, relative department should reasonably choose the logistics centre in Nanchang and deliver the relief supplies to other city and county timely.

The second measure is to ensure the smooth flow of the communication and information during the period of the disaster relief. A good example is to set up a special communication network of the snow disaster information based on a public communication network. In addition, the power group can response to the disaster quickly, 
timely, and effectively through the fast, real-time and accurate flow of the information in the logistics system. Therefore, the relief supplies can be delivered to disaster areas rapidly and ensure the normal life of people.

The third measure shows that a supporting and decision-making role of the logistics information system. It can assist the power companies to collect information and predict accurately the disaster in the future, which can effectively control disaster losses.

The fourth measure is to strengthen the response to emergencies. For instance, increasing reserve power of emergency and the appliance of GPS and VOIP. In addition, it is necessary to storage some materials such as grain, coal and so on. For those disaster areas of grid damaged, local government can utilize the coal to generate the power and stabilize the emotions of people.

\subsection{The Shortages of Recovery and Reconstruction of Jiangxi Power Grid Mainly Demonstrate in the Following Aspects}

The first shortage lies in the predictable capability for the disaster. For example, local government should construct a comprehensive and systematic infrastructure before the large natural disasters happened rather than regret it later. Thus, it is necessary to improve the capability of resisting disaster.

The second one is the immaturity emergency response system and mechanism. In order to improve the abilities of handling emergencies, the power grid of China should strengthen the construction of the emergency response system. It can assist relative department to achieve a rapid response rather than waiting for approval from superiors.

The third one is the lack of the research on the features and patterns of natural disasters under the modern conditions and the capacity of disaster prevention and reduction. It is unbelievable that the storm left such chaos under advanced science and the early warning system. Therefore, this means the issues existed in the whole system.

The fourth one is in the repairing and examining work of power grid for a long term. For instance, the trouble wire should be found quickly and changed into the new one instead of waiting for remedy of the issue.

The fifth one is short of the innovation or import of advanced technology, such as the research on the technology of ice melting and anti icing. Government also should improve the level of disaster prevention and alleviation and the foundation of scientific decision-making. The National Disaster Reduction centre as a basis established a shared platform of disaster information and information exchange services between departments. This can achieve an improvement of the information sharing mechanism.

The last one is the insufficiency in the overall planning of emergency resources and centralized management, with particular attention to the linkage and training of the social emergency system. In order to improve the capability of the management efficiency and dealing with emergency, it is time to establish and lift the standards of the emergency and repairing work, quantize disaster grade.

The State Power Corporation of China has been issued "An emergency treatment counter plan about the power equipment of Jiangxi Province Electric Power Company in wide range damage” on 21st June 2006. The main purpose of the plan is to handle and control a large fan power facilities surrounding damage accurately and timely. Meanwhile, the plan also is to minimize and eliminate the impact and losses of the accident, ensure safety in production of the grid and maintain the electricity supply of the society. However, the content of the plan is the principle provisions and lack of the implementation capacity of provisions. Thus, it is necessary to formulate specific measures when the emergency material cannot be timely supplied by the province [2].

These measures involve in the following aspects. First of all, the department of material assurance could rush to the China State Grid Corp Bidding Center for a support. Then the Center could collect the inventory survey of other provinces' electric power company and pole manufactures and provides the information to the material assurance department of anti ice rescue in Jiangxi Province. Secondly, Central China Power Supplies Company should play a role of regional advantages and keep close to the engineering department and technology department. Meanwhile, the company also should maintain a communication with those key manufacturers who mainly produce the facilities and components of accident repair. This can ensure the disaster relief supplies and relevant personnel in disaster area timely and accurately. Overall, Jiangxi Province Electric Power Company should prearrange the relief materials and equipments, keep contact with the preferred and alternative suppliers, and power grid supply department of other provinces to ensure the scheduling purchase and distribution of ur- 
gent supplies. Finally, the optimum scheme of the emergency supply can be established.

\section{The Construction of Emergency Logistics Information System of the State Power Corporation of China}

\subsection{The Overall Planning of Emergency Logistics System}

The State Power Corporation of China has adopted an online bidding system. However, the bidding is only a part of the power material management system. In order to achieve the comprehensive information of the power material management, the power company proposed a future programming of the emergency logistics information system which is based on a successful operation of online bidding system and a management system of the power material.

The planning is based on a platform of the electronic commerce-online bidding system [3]. At the same time, the planning can construct a safety material management and circulation system for meeting the comprehensive needs of power material through the design, R \& D and requirements analysis of developing logistics management information system. It also involves the following details: the approval of construction project; material procurement; manufacturing; storage and transportation; financial capital; strengthen the management of supply chain; and business cooperation.

With regard to the requirements of future development and current situation of informatization of the State Power Corporation of China, the platform will be embedded up to ERP system of the province's network, down into ERP system of the power supplies manufacturers or traders and transverse embedded material management institutions of existing OA and financial system.

The power company and power supply company can rapidly start the information platform as the emergency logistics management information system when the bad weather coming again.

\subsection{The Construction and Planning of Emergency Logistics Information System [4]}

1) The strengthening of the foundation of the emergency logistics informatization.

Jiangxi Province Power Company should establish an efficient logistics information network, comprehensive command network, transport information network and storage information network and so on. This will depend on a public information platform. These tasks include a construction of the information standardization, unified code, and standard file format of information transport. This is good for the improvement of the basic database and the collection and update of the detailed data about the road, supplier and power materials.

2) The construction of the framework of emergency logistics information system

The essay provides a comprehensive framework of the assurance system of emergency logistics information, as shown in the Figure 1. To begin with, it is to establish a sensitive warning mechanism. There is often a sign before the appearance of the emergency logistics, such as the snow weather of the late January in the southern area, the abnormal phenomenon of electric power facilities, the fall of pole (tower) and off (out) line. These phenomena provide a possible of warning system of the emergency logistics information. Therefore, it is time to strengthen the research on the critical index. This can lift the sensitive warming capability of the emergency information system.

Secondly, it is to set up a normative emergency changeover mechanism. The key point of information assurance lies in the junction of the normal situation converted into emergency situation. These different emergency tasks have some differences between corresponding information flow and the flow content. However, the deployment and operation process of information system is similar. Hence, it is necessary to establish a standardized information security mechanism and prevent the confusion and disorder.

Thirdly, it is to establish a scientific decision-making mechanism. The first function of the information assurance is to provide the information of the different parts of emergency logistics system. So the information system can be more widely participated in the decision-making. In order to improve the assurance efficiency of emergency logistics, it is necessary to fully understand the principle of the logistics operation, construct an optimization module and optimize the daily management of logistics procedure.

Fourthly, it is to construct a feedback assessment mechanism timely. There are some problems in the different part of emergency logistics, for example, the problem of the effectiveness, bottleneck and short board. These issues require the answer timely and correctly. The effective feedback evaluation system can reflect the weak part 


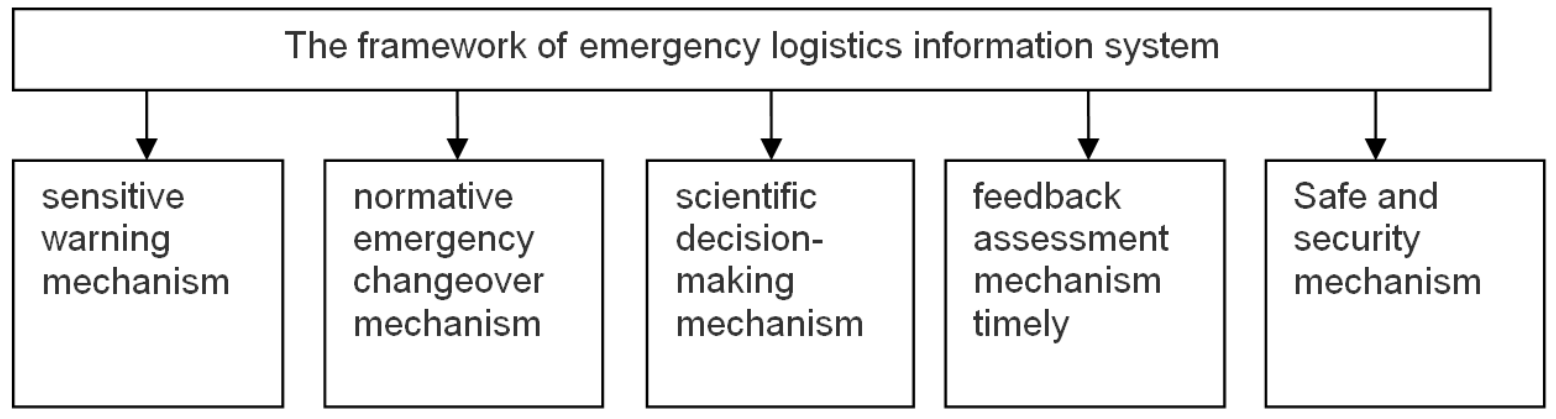

Figure 1. The framework of emergency logistics information system.

in the logistics system timely and provide a possibility of the correction of the errors and procedure.

Fifthly, it is to establish a safe and security mechanism of the information. The emergency logistics are closely related to the stability of a country. The safety of the information should be concerned because of the sensibility of the politics. The existences of the computer virus and hackers force us to strengthen the protection of the emergency logistics information system. These measures include the construction of the protection institution and the technical support department firstly, then the encryption and physical isolation of the significant data and the punishment of the personnel who leaks and damage security system.

\subsection{The Construction of the Efficient and Reliable Emergency Logistics Assurance Information Platform [5]}

The construction of the emergency logistics support platform includes hardware system and software system. However, the emergency logistics information system is vital part in the construction of the software system. The emergency logistics information system is a special information system to meet the emergency relief work. It plays an important role in the emergency logistics activities. The optimization of emergency logistics system and the methods and channels of the logistics links depend on the logistics information of the accuracy, for instance, a reasonable choice of transportation, the optimal reserve capacity and the choice of the transportation route. Consequently, the emergency logistics information system plays a very important role.

The main function of emergency logistics information systems involve: The first function is the organization and direction of the emergency logistics. The emergency logistics information system provides measures of information processing for the collection and analysis of data, the preparation of logistics planning, the division of the relationship of the logistics supply chain, the organization of the logistics business and coordination of the emergency relief work.

The second function is the handling capability of the emergency logistics. It indicates the collection and management of the relevant information, such as the quantity, quality and distribution of the all kinds of emergency supplies, the capability of the storage and receives and dispatch in the distribution center of emergency logistics and the throughput capacity of the dock port.

The third one is the control of emergency logistics resources. It mainly shows the acquisition and processing of the correlative information, for instance the information of the main emergency supplies, funs, facilities, equipment and land.

The fourth one is the dynamic control and direction. It includes the obtainment and handing of the related information about the emergency logistics personnel, equipment, emergency supplies, and the category, quantity, quality, location, disposal and organization of the transportation.

The fifth function is the processing of emergency logistics business. It represents the acquisition and management of the operation information of emergency logistics. For example online statistics, plan, allot, settlement and document processing.

The last one is the function of the assistance decision. It provides an optimal decision and the choice for the emergency command department and personnel through various models of emergency logistics. The emergency logistics system is composed of several subsystems which involve the monitoring and forecast system of the disaster, the collection and analysis system of the information, the management system of the warehouse, transport and distribution, decision support system and a comprehensive database. 


\section{Conclusion}

The level of the emergency logistics informationization is low in the large state-owned enterprises at present. It is difficult to solve the requirements of the emergency. Therefore, it is urgent to establish a set of effective emergency logistics system and improve the mechanism of the early warning, conversion, processing and feedback. In addition, the government should pay attention to the construction of information infrastructure of the society and the talents training of the logistics informatization. It is believed that the development and improvement of the emergency logistics system will ensure the smooth flow of the enterprises' materials and the stability of society.

\section{References}

[1] Wengliang, W. (2003) The Construction of Information System in the Emergency Logistics. China Logistics \& Purchasing.

[2] Changtan, X. (2008) the Construction of Emergency Logistics System. Modern Property Management, 7, $102-103$.

[3] Papadakis, Y. (2003) Supply Chain Security without Tears. Supply Chain Management Review, 7, 12-20.

[4] Yuhong, J. (2007) Research on the Combination of the Emergency Logistics Assurance and Military Logistics. Journal of Logistical Engineering University.

[5] Lan, F. (2009) Design of Logistics Information System of Agricultural Products. China Business and Market. 